\title{
Mammary cancer: Sneak peek to thyroid nodules
}

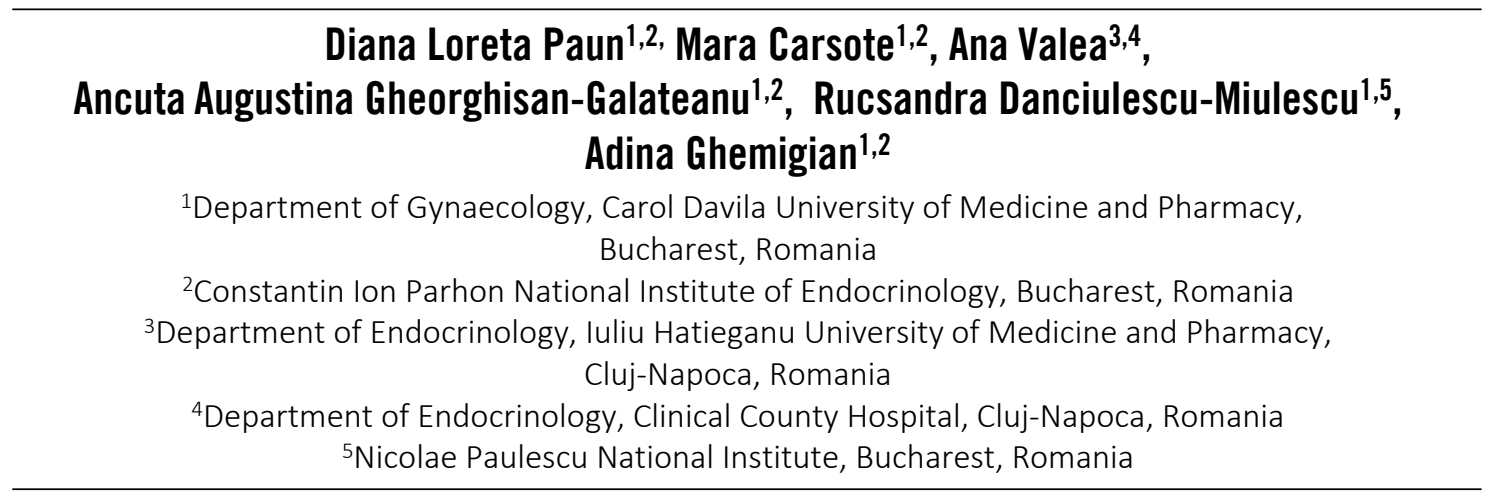

\begin{abstract}
Breast cancer has a worldwide increasing incidence and once the diagnosis is done a screening is performed using method like ultrasound, computed tomography etc in order to assess disease spreading, according to the mammary malignancy's stage. During this type of evaluation, a thyroid condition might be detected. Generally, $50-70 \%$ of adult population has a thyroid nodule of different dimensions, usually with a very low clinical relevance and a very good prognosis. If the pathogenic correlation between a thyroid nodule and the breast tumour is indeed sustained this is still a matter of debate. Our purpose is to introduce a series of subjects associating non-syndromic mammary cancer and thyroid nodules of various types. The use of thyroid ultrasound in patients with mammary cancer is mandatory. Most of thyroid nodules are incidental but some thyroid pathologies may actually be linked to breast malignancy.
\end{abstract}

Keywords: breast cancer, ultrasound, thyroid nodule

\section{INTRODUCTION}

Breast cancer has an increasing incidence and once the diagnosis is established a screening using ultrasound, computed tomography or magnetic resonance imagery for adequate assessment of the disease spreading is frequently useful, according to the mammary malignancy's stage $(1,2,3)$. On the other hand, if performed imagery, $50-70 \%$ of adult population has a thyroid nodule of different dimensions, usually with a very low clinical relevance $(4,5,6)$. Thus in particular cases priorly confirmed with a cancer diagnosis, the risk of incidental finding regarding a thyroid nodule is very high $(4,5,6)$. Clinical detection in general population reveals that $5 \%$ of women coming from non-endemic areas have a thyroid nodule (5). The incidence is age related (5). Overall, the risk of thyroid cancer in a thyroid incidentaloma is $7-15 \%$ (5). The term of thyroid "incidentaloma" is not routinely used for thyroid as seen in adrenal and pituitary incidentaloma, being preferred a rather general term of thyroid "nodule" $(7,8,9)$. If the pathogenic correlation between a thyroid nodule and the breast tumour is indeed sustained this is still a matter of debate $(10,11,12)$. The risk of thyroid metastasis in breast cancer is extremely low while the synchronous diagnosis of a second malignancy like a differentiated thyroid cancer is considered in majority of cases circumstantial, except for rare common genetic background $(13,14,15)$.

\section{AIM}

Our purpose is to introduce a series of subjects associating non-syndromic mammary cancer and thyroid nodules. Also, particular endocrine aspects as bone status or hyperprolactinemia are displayed in addition to mammary malignancy.

\section{METHOD}

This is a case presentation. The gynaecological endocrine and oncologic profile is provided. 


\section{RESULTS}

\section{Case presentation 1}

This is a 38-year old female who is diagnosed with breast cancer of ductal type two years ago. She had total mastectomy done at that time, irradiation and chimiotherapy and she is under tamoxifen since then (surgical menopause was induced at age of 37). The medical family history reveals a mother with toxic multinodular goitre, a cousin with breast cancer also with mammary neoplasia. No genetic test was done. She recently underwent an evaluation and hypercalcemia as well as small thyroid nodules were detected. Endocrine and oncologic evaluation confirmed bone metastases and therapy with monthly zolendronic acid was started. A level of mildly calcium elevation was stationary within next few months: total serum calcium of $10.6 \mathrm{mg} / \mathrm{dl}$ (normal ranges between 8.4 and 10.2 $\mathrm{mg} / \mathrm{dl}$ ), ionic calcium of $4.3 \mathrm{mg} / \mathrm{dl}$ (normal values between 3.9 and $4.1 \mathrm{mg} / \mathrm{dl}$ ). Suppressed parathormone levels and adequate 25-hydroxyvitamin D are found. Lumbar DXA (Dual-Energy X-Ray Absorptiometry) showed adequate values of bone mineral density according to subject age (Fig. 1).

When it comes to thyroid panel, the ultrasound detected normal lobes (right of 1.5 by 1.3 by 1.7 $\mathrm{cm}$, left of 1.5 by 1.4 by $3.2 \mathrm{~cm}$, with hipoechoic pattern) and 2 hypoechoic nodules of 0.9 by 0.4 $\mathrm{cm}$, respective of 0.8 by $0.3 \mathrm{~cm}$ (on the left side), without local lymph nodes involvement as shown by anterior cervical ultrasound. Normal thyroid function, calcitonin levels and thyroid anti-bodies are identified. Annual thyroid ultrasound follow-up is recommended.

\section{Case presentation 2}

A 65-year old non-smoking female, resident in endemic area, is diagnosed three years ago with right breast cancer. Surgery and pre-operatory chimiotherapy was done and she has been treated with anastrozol for the last 3 years. She associates high blood pressure and hyperlipemia treated with oral medication. She has menopause at age of 48 years. In the mean time a routine thyroid ultrasound showed a multinodular goitre with normal thyroid function. On current admission, TSH, calcitonin are normal while thyroid ultrasound reveals a right lobe of 5 by 2.1 by $5 \mathrm{~cm}$, a left lobe of 4.5 by 2 by $1.4 \mathrm{~cm}$, multiple nodules on the right lobe of 0.2 by $0.4 \mathrm{~cm}$, of 0.5 by $0.3 \mathrm{~cm}$, of 1.22 by $0.8 \mathrm{~cm}$ (a recent increase when compared to previous examination), respective of 0.6 by $0.4 \mathrm{~cm}$, of 0.3 by $0.5 \mathrm{~cm}$ at the level of left lobe (Fig. 2).

Fine needle aspiration was done for the largest nodule and it was found a low risk profile. Other endocrine assessments showed: an intial value of prolactin higher than upper normal limit (of 27.7 $\mathrm{ng} / \mathrm{ml}$, normal less than $20 \mathrm{ng} / \mathrm{ml}$ ) which became normal during follow-up, and bone profile showed osteopenia (a lumbar T-score of -1.6 SD) at central DXA (Fig. 3).

Supplements with calcium and vitamin D in addition to weekly alendronate were recommended since criteria for anti-resorptive medication are reached at this moment and at least annual DXA is required.

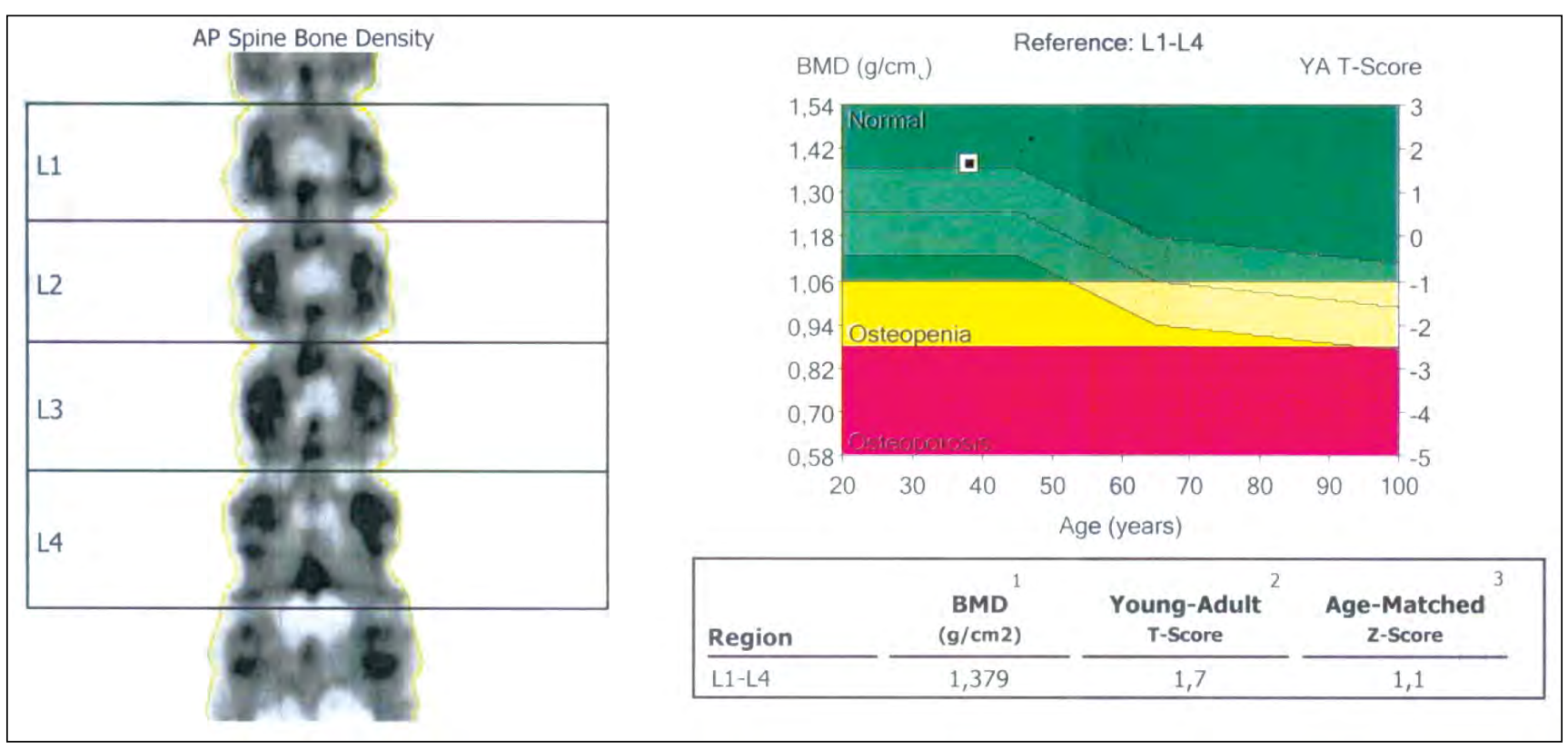

FIGURE 1. Lumbar DXA on a 38-year old female with bone metastasis in addition to breast cancer-related hypercalcemia: adequate values for age and menopausal status (surgical menopause since the age of 37 years) 


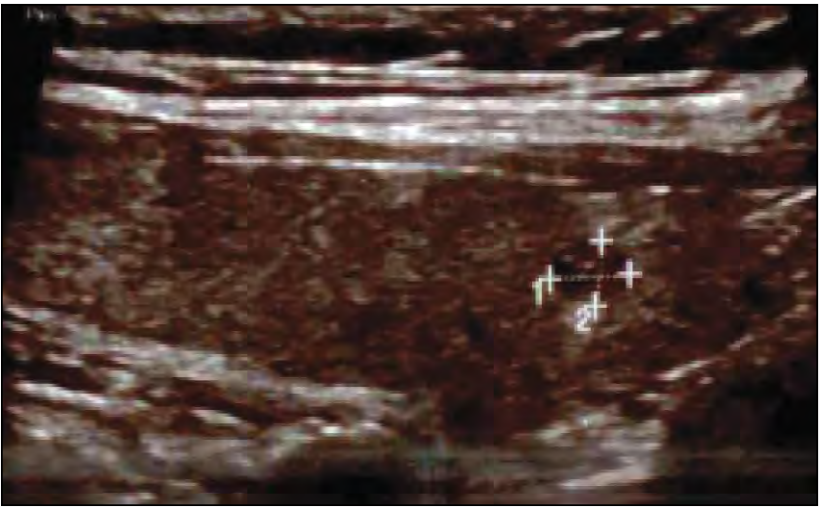

FIGURE 2A. Thyroid ultrasound: multinodular aspect on a 65-year old female with breast cancer. This is the right thyroid lobe and a small nodule of 0.5 by $0.3 \mathrm{~cm}$

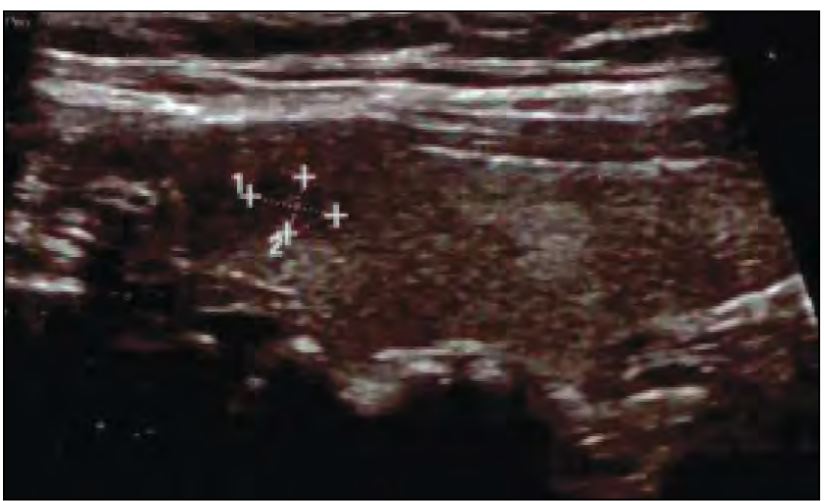

FIGURE 2B. Left thyroid lobe with a small nodule of 0.4 by $0.3 \mathrm{~cm}$

\section{Case presentation 3}

A 53 year old female has mammary breast cancer which was treated 3 years ago, only a few months after she entered spontaneous menopause. She had mastectomy, chimiotherapy and started daily letrozole until present time. Her medical records from the diagnosis also reveal: at aromatase inhibitor initiation, the patient had osteoporosis (a lumbar L1-4 T-score of -2.5 SD with bone mineral density of $0.885 \mathrm{~g} / \mathrm{sqcm}$ ) thus weekly alendronat and daily vitamin $\mathrm{D}$ were associated; she was accidently found with multinodular goitre with suppressed TSH requiring daily thiamazol therapy to control the thyroid function. The initial ultrasound showed a thyroid enlargement: right lobe of 7.5 by 2.2 by $3.6 \mathrm{~cm}$ and left lobe of 7.8 by 3.1 by $3.6 \mathrm{~cm}$ with inhomogeneous pattern and multiple nodules of various sizes. Right lobe had the largest nodule of $2.9 \mathrm{~cm}$ with a microcalcification which sugested a papillary carcinoma. After normal thyroid function was achieved based on anti-thyroid medication, the patient was referred for total thyroidectomy. No confirmation of differentiated thyroid cancer was done. Lifelong thyroid substitution therapy is necessary.

\section{DISCUSSION}

The accidental detection of one or multiple thyroid nodules in patients diagnosed with breast cancer requires periodic check-up and fine needle aspiration in cases of nodules larger than $1 \mathrm{~cm}$ (10). Case 2 has other endocrine anomaly with a potential link regarding the breast condition. A part from thyroid blood assays and ultrasound, hyperprolac-

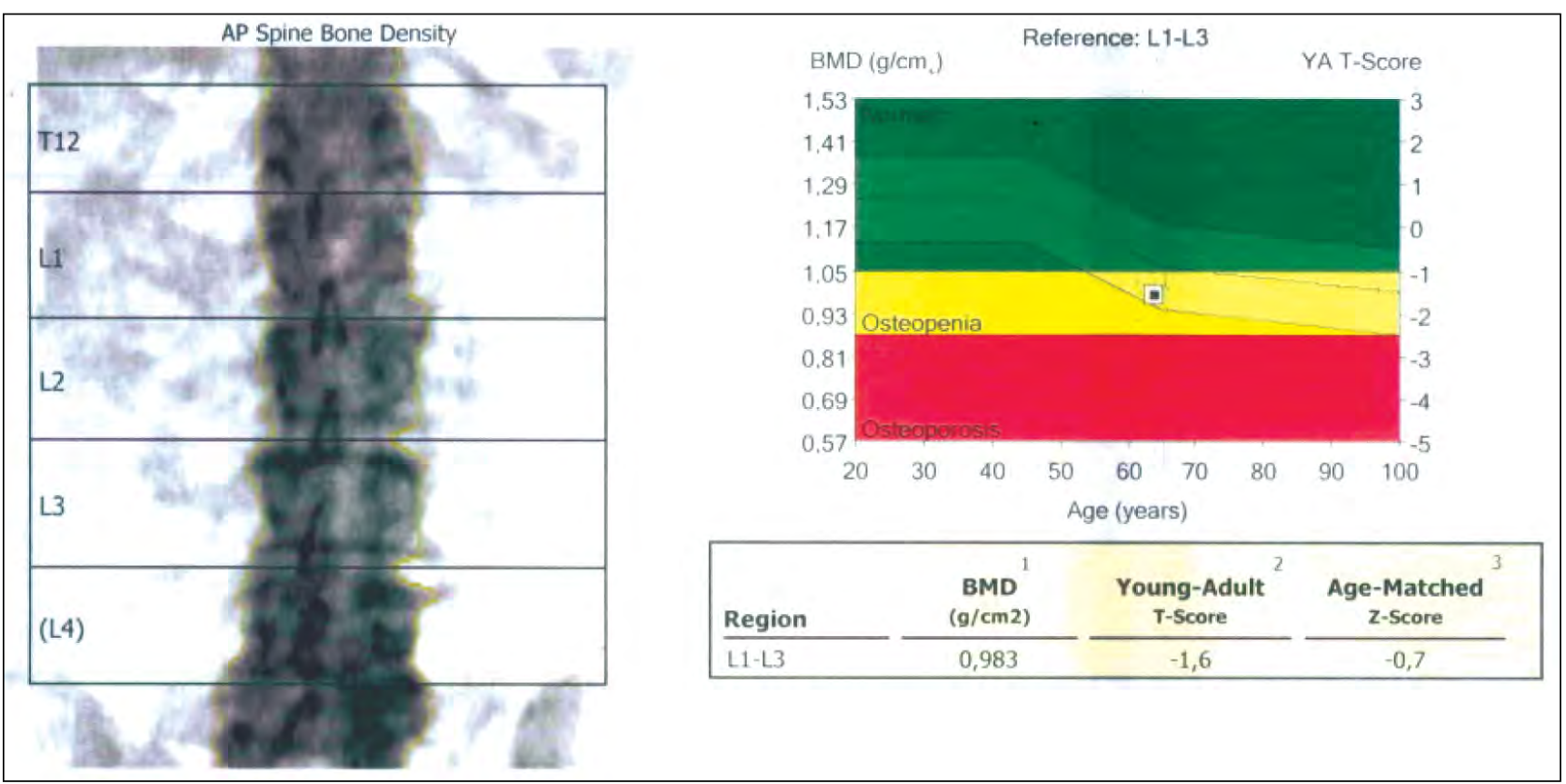

FIGURE 3. Lumbar DXA shows osteopenia in a menopausal woman under aromatase inhibitor 
tinemia may be caused by the presence of the mammary tumour itself (or other lesions like large cysts) but it is a rare event (except for lactation- and pregnancy-related mammary cancer) $(16,17,18)$. Some observations suggested that hyperprolactinemia is a modulator and a growth factor for mammary cells from the tumour $(16,17,18)$. Moreover, the subject number 2 and 3 had decreased bone mass according to central DXA examination. This is another particular endocrine aspect in patients with mammary cancer under therapy with aromatase inhibitors who may also associate premature iatrogenic menopause, also a contributor to bone damage $(19,20)$. Under these circumstances a close evaluation of bone loss status is necessary in order to decide anti-osteoporotic therapy $(19,20)$. Case 3 had microcalcifications at thyroid ultrasound microcalcification which are very suggestive for papillary thyroid cancer even in the absence of a large nodule; the

\section{REFERENCES}

1. Matsen $C B$, Neumayer $L A$. Breast cancer: $A$ review for the general surgeon. JAMA Surg 2013;148(10):971-9.

2. Donepudi MS, Kondapalli K, Amos SJ, Venkanteshan P. Breast cancer statistics and markers. J Cancer Res Ther 2014;10(3):506-11.

3. Lima ZS, Ebadi MR, Amjad G, Younesi L. Application of Imaging Technologies in Breast Cancer Detection: A Review Article. Open Access Maced J Med Sci 2019;7(5):838-848.

4. Brito JP, Gionfriddo MR, AI Nofal A, Boehmer KR, Leppin AL, Reading C, Callstrom M, Elraiyah TA, Prokop LJ, Stan MN, Murad MH, Morris JC, Montori VM. The accuracy of thyroid nodule ultrasound to predict thyroid cancer: Systematic review and meta-analysis. J Clin Endocrinol Metab 2014;99(4):1253-63.

5. Paschou SA, Vryonidou A, Goulis DG. Thyroid nodules: A guide to assessment, treatment and follow-up. Maturitas 2017;96:1-9.

6. Davenport C, Alderson J, Yu IG, Magner AC, M O'Brien D, Ghiollagain MN, Kileen S, Heneghan M, Sabah M, Leen E, McDermott JH, Sreenan S, Hickey N, Kyaw-Tun T. A review of the propriety of thyroid ultrasound referrals and their follow-up burden. Endocrine. $2019 \mathrm{Apr}$ 6. doi: 10.1007/s12020-019-01920-1. (Epub ahead of print)

7. Langer JE. Sonography of the Thyroid. Radiol Clin North Am 2019:57(3), pp. 469-483.

8. Maxwell C, Sipos JA. Clinical Diagnostic Evaluation of Thyroid Nodules. Endocrinol Metab Clin North Am 2019;48(1):61-84.

9. Kaliszewski K, Diakowska D, Ziętek M, Knychalski B, Aporowicz M, Sutkowski K, Wojtczak B. Thyroid incidentaloma as a "PAIN" phenomenon - does it always require surgery? Medicine (Baltimore) 2018;97(49):e13339.

10. Nielsen SM, White MG, Hong S, Aschebrook-Kilfoy B, Kaplan EL, Angelos P, Kulkarni SA, Olopade OI, Grogan RH. The Breast-Thyroid Cancer Link: A Systematic Review and Meta-analysis. Cancer Epidemiol Biomarkers Prev 2016;25(2):231-8.

11. Mortezaee K, Ahmadi A, Haghi-Aminjan H, Khanlarkhani N, Salehi E, Shabani Nashtaei M, Farhood B, Najafi M, Sahebkar A. Thyroid function following breast cancer chemotherapy: A systematic review. J Cell Biochem. 2019 Apr 25. doi: 10.1002/jcb.28771. (Epub ahead of print)

12. Uzair ID, Conte Grand J, Flamini MI, Sanchez AM. Molecular Actions of Thyroid Hormone on Breast Cancer Cell Migration and Invasion via Cortactin/N-WASP. Front Endocrinol (Lausanne) 2019;10:139.

13. Durmo R, Albano D, Giubbini R. Thyroid metastasis from breast cancer detected by 18F-FDG PET/CT. Endocrine. 2019 Apr 1. doi: 10.1007/s12020-019-01916-x. (Epub ahead of print) risk is higher in younger patients and if the autoimmune thyroid background is positive (21). However, in this case there was no confirmation of thyroid malignancy after pathological report was performed. Moreover, the autoimmune thyroid background is relatively frequent in adult population and it cannot be linked in particular with mammary neoplasia based on most observations (22). This type of thyroid nodules that are accidentally detected underlines the general term of "incidentaloma" which is commonly used for adrenal and pituitary gland $(23,24,25)$.

\section{CONCLUSION}

The use of thyroid ultrasound in patients with mammary cancer is mandatory. Some thyroid nodules had an irrelevant clinical significance but some thyroid conditions may be linked to breast malignancy.

14. Plonczak AM, DiMarco AN, Dina R, Gujral DM, Palazzo FF. Breast cancer metastases to the thyroid gland - an uncommon sentinel for diffuse metastatic disease: a case report and review of the literature. J Med Case Rep 2017;11(1):269.

15. Lei K, He X, Yu L, Ni C, Chen H, Guan D, Sun K, Zou H. Breast cancer prognosis is better in patients who develop subsequent metachronous thyroid cancer. PLoS One 2019;14(5): e0215948.

16. Underdal MO, Salvesen $\varnothing$, Schmedes AV, Andersen MS, Vanky E. Prolactin and breast increase during pregnancy in PCOS - linked to long-term metabolic health? Eur J Endocrinol. 2019 Apr 1. pii: EJE-19-0002.R1. doi: 10.1530/EJE-19-0002. (Epub ahead of print)

17. López-Ozuna VM, Hachim IY, Hachim MY, Lebrun JJ, Ali S. Prolactin modulates TNBC aggressive phenotype limiting tumorigenesis. Endocr Relat Cancer. 2019 Jan 1. pii: ERC-18-0523.R1. doi: 10.1530/ ERC-18-0523. (Epub ahead of print)

18. Poiana C, Chirita C, Carsote M, Hortopan D, Goldstein A. Galactocele and prolactinoma - a pathogenic association? Maturitas 2009; 62(1):98-102.

19. Cheung AM, Heisey R, Srighanthan J. Breast cancer and osteoporosis. Curr Opin Endocrinol Diabetes Obes 2013;20(6):532-8.

20. Salzman B, Collins E, Hersh L. Common Breast Problems. Am Fam Physician 2019;99(8):505-514.

21. Whittle C, García M, Horvath E, Slater J, Carrasco C. Thyroid Microcalcifications in the Absence of Identifiable Nodules and Their Association With Thyroid Cancer. J Ultrasound Med 2019;38(1):97-102.

22. Paun DL, Petris R, Carsote M, Ferechide D, Poiana C. Aspecte particulare in bolile autoimune tiroidiene. Romanian Journal of Medical Practice 2013;8(3):173-177.

23. Gheorghiu ML, Hortopan D, Dumitrascu A, Caragheorgheopol A, Stefanescu A, Trifanescu R, Niculescu D, Baciu I, Carsote M, Poiana C, Badiu C, Coculescu M. Age-related endocrine tumors: Non-functioning adrenal tumors as compared to pituitary adenomas. Acta Endocrinologica-Bucharest. 2009;5(3):371-383.

24. Shi Y, Li X, Ran L, Arshad B, Li H, Xu Z, Zhao C, Wu Y, Wu H, Chen $\mathrm{H}$, Li HY, Wu KN, Kong LQ. Study on the status of thyroid function and thyroid nodules in chinese breast cancer patients. Oncotarget. 2017; 8(46):80820-80825.

25. O'Sullivan JW, Muntinga T, Grigg S, loannidis JPA. Prevalence and outcomes of incidental imaging findings: Umbrella review. BMJ. 2018; 361:k2387. 